\title{
A Experiência da Paternidade e o Envolvimento Paterno no Contexto da Síndrome de Down ${ }^{1}$
}

\author{
Camila Guedes Henn ${ }^{2}$ \\ Cesar Augusto Piccinini \\ Universidade Federal do Rio Grande do Sul
}

\begin{abstract}
RESUMO - O objetivo deste estudo foi investigar, através de uma abordagem qualitativa, o envolvimento paterno e a experiência da paternidade no contexto da Síndrome de Down (SD). Foram entrevistados seis pais de crianças com SD, cujos filhos tinham idades entre nove meses e três anos e três meses. Os resultados revelaram que os pais participavam ativamente das atividades e cuidados dos filhos, sendo responsáveis por diversas tarefas que os envolviam, embora o tempo disponível para estar com eles fosse restrito em função do trabalho. De qualquer forma, apesar das dificuldades, tanto objetivas (financeiras, tempo, emprego), como mais subjetivas (aceitação, tristeza, preocupação), eles demonstraram uma boa adaptação ao filho com SD, conseguindo exercer seu papel de pai.
\end{abstract}

Palavras-chave: envolvimento paterno; Síndrome de Down; paternidade.

\section{Paternal Experience and Paternal Involvement in the Context of the Down Syndrome}

\begin{abstract}
The aim of the present study was to investigate, through a qualitative approach, paternal involvement and paternal experience in the context of the Down Syndrome (DS. More specifically, it aimed to understand the impact of DS on paternal involvement and experience. Six fathers of children with DS were interviewed, whose children were between nine months and three years and three months. The results indicated that fathers had been participating actively in children's activities and caretaking, being responsible for several tasks, although the available time to spend with them was restricted because of their jobs. In spite of both objective (financial, time, job) and subjective difficulties (acceptance, sadness, preoccupation), they demonstrated good adaptation to their child with DS, being able to carry out their role as a father.
\end{abstract}

Keywords: paternal involvement; Down Syndrome; fatherhood.

A visão do pai ${ }^{3}$ como alguém que desempenha unicamente o papel de provedor na vida da família e dos filhos vem sendo substituída pela percepção de que ele é um membro que pode exercer inúmeros papéis significativos, dentre os quais o de companheiro, protetor, cuidador, modelo, orientador e professor (Lamb, 1997). Por outro lado, mesmo com a emergência deste novo pai, Lewis e Dessen (1999) ressaltam que qualquer análise da paternidade precisa começar com a observação de que em poucas sociedades o pai assume os cuidados rotineiros com relação às crianças. Os homens continuam se representando e sendo representados por papéis fora do centro das interações familiares, o que pode ser justificado pelas pressões do trabalho, pela falta relativa de recompensa por seu engajamento nos cuidados das crianças e pelas sutis negociações entre os parceiros sobre a parte a ser desempenhada pelo homem na família.

1 O presente artigo é baseado em parte da dissertação de mestrado da primeira autora, intitulada $O$ envolvimento paterno e a experiência da paternidade no contexto da Síndrome de Down, realizada sob orientação do segundo autor e apresentada no PPG - Psicologia da UFRGS.

2 Endereço para correspondência: UFRGS - Instituto de Psicologia, Rua Ramiro Barcelos, 2600, sala 111. Porto Alegre, RS, Brasil. CEP: 90035-003. Fone: (51) 33085058.E-mail: camilahenn@hotmail.com

3 Para fins de clareza, no presente artigo o termo pai(s) será utilizado apenas para designar o pai, enquanto o termo "pai(s) e mãe(s)" será utilizado quando se estiver fazendo referência a ambos os genitores.
De acordo com esses autores, talvez por isso o pai seja notado pela sua ausência, principalmente em relação à vida de crianças pequenas, o que fortalece um estereótipo negativo sobre seu papel dentro da família. Nesse sentido, um importante avanço no que concerne às pesquisas sobre paternidade foi o desenvolvimento do construto de envolvimento paterno, proposto por Lamb, Pleck, Charnov e Levine (1985), que chamou atenção para uma dimensão do comportamento dos pais até então negligenciada em estudos anteriores (Pleck, 1997). Embora a definição inicial deste construto estivesse relacionada à quantidade de tempo que os pais despendem com seus filhos, sem preocupação com o conteúdo do envolvimento, foi este mesmo autor quem advertiu sobre a necessidade de se repensar o conceito para que fossem incluídas as dimensões qualitativas do comportamento paterno. Surgiu, assim, o conceito de envolvimento paterno positivo que inclui, além do nível quantitativo do envolvimento paterno, também a preocupação com o conteúdo e a qualidade desse envolvimento (Pleck, 1997).

O envolvimento paterno, conforme Lamb, Pleck, Charnov e Levine (1985) pode ser visto a partir de três componentes: interação, acessibilidade e responsabilidade. A interação é entendida como o contato direto do pai com a criança, através de cuidados e atividades compartilhadas; já acessibilidade refere-se à presença e à disponibilidade do pai para a criança, acontecendo ou não a interação direta entre eles; 
Tabela 1. Dados Demográficos dos Participantes

\begin{tabular}{|c|c|c|c|c|c|c|c|}
\hline Caso & Idade Pai & Escolaridade & Profissão & Situação Conjugal & $\begin{array}{l}\text { Tempo } \\
\text { Diagnóstico }\end{array}$ & $\begin{array}{l}\text { Idade } \\
\text { criança }\end{array}$ & $\begin{array}{l}\text { Sexo } \\
\text { Criança }\end{array}$ \\
\hline P1 & 26 & Sup. Incomp. & Aux. Laborat. Inform. & Moram juntos & Gestação (3m) & $9 \mathrm{~m}$ & Masc. \\
\hline $\mathrm{P} 2$ & 46 & Pós-Grad. & Professor & Moram juntos & Após nasc. & $3 \mathrm{a} 3 \mathrm{~m}$ & Masc. \\
\hline P3 & 40 & Fund. Incomp. & $\begin{array}{l}\text { Aux. Escritório (desem- } \\
\text { pregado) }\end{array}$ & Moram juntos & Após nasc. & 1a $4 \mathrm{~m}$ & Fem. \\
\hline P4 & 26 & Médio Comp. & Gerente de loja & Moram juntos & Após nasc. & 1a $10 \mathrm{~m}$ & Fem. \\
\hline P5 & 39 & Fund. Incomp. & Vendedor & Moram juntos & Gestação (3m) & 1a $11 \mathrm{~m}$ & Fem. \\
\hline P6 & 30 & Médio Comp. & Entrevistador & Moram juntos & Após nasc. & 1a $2 \mathrm{~m}$ & Masc. \\
\hline
\end{tabular}

e, a responsabilidade, refere-se ao papel que o pai exerce nos cuidados com a criança, como ao selecionar babás, marcar consultas com pediatras e determinar se a criança precisa de roupas novas. Para estes autores, dentre os possíveis fatores que influenciariam o envolvimento paterno, pode-se ressaltar: a motivação, que seria o desejo de envolvimento deste pai, podendo estar relacionado, entre outros fatores, à quantidade de envolvimento que seus próprios pais tiveram para com ele; as habilidades, que são necessárias para o sucesso e prazer nos cuidados da criança; o apoio, que é a aprovação do envolvimento paterno por outras pessoas, tais como a esposa, a mãe e os colegas de trabalho; e os fatores institucionais, como o emprego deste pai que poderia impedir um maior envolvimento com a criança.

Embora nos últimos anos tenham aparecidos muitos artigos sobre o papel do pai em diferentes contextos, poucos são os que investigaram a paternidade em crianças com deficiência mental (Lamb \& Billings, 1997) e, particularmente, com Síndrome de Down (SD), como mostrado em recente revisão da literatura (Henn, Piccinini \& Garcias, 2008). Além disto, os estudos existentes sobre o assunto apresentam, muitas vezes, limitações, pois seus dados se baseiam freqüentemente em impressões clínicas, medidas de atitudes parentais, ou relatórios maternos a respeito das reações emocionais e comportamentais de seus companheiros. Além disso, segundo Lamb e Billings (1997), os estudos que exploram o envolvimento paterno com os filhos com deficiência apresentam resultados ainda pouco consistentes.

Quando se fala especificamente sobre SD, são poucas as investigações em que o pai está presente (Henn \& cols., 2008; Dessen \& Silva, 2000). Por exemplo, a revisão da literatura nacional e internacional realizada por Dessen e Silva (2000), envolvendo famílias de crianças com deficiência mental, revelou que, no período de 1985 a 1999, a participação do pai só foi destacada em estudos estrangeiros que também envolviam a mãe, enquanto os poucos estudos nacionais destacaram a díade mãe-criança.

Dentro deste contexto, os poucos artigos encontrados na revisão de Henn e cols. (2008) revelaram que os pais de crianças com SD apresentam níveis mais baixos de estresse do que as mães, ou do que pais de crianças com outros tipos de deficiência como autismo e paralisia cerebral. Dificuldades foram apontadas, especialmente quanto a questões financeiras, de planejamento familiar, assim como restrições familiares e preocupações a longo prazo com os cuidados dos filhos. Entretanto, eles também demonstraram que os pais possuíam uma visão positiva da personalidade de seus filhos, bem como uma boa adaptação às exigências e cuidados demandados por eles.

Nesse sentido, considerando a importância deste tema e os poucos estudos existentes, o presente estudo teve por objetivo investigar o envolvimento paterno e a experiência da paternidade no contexto da SD. Mais especificamente procurou-se compreender o impacto que a SD exerce sobre este envolvimento e experiência paterna.

\section{Método}

\section{Participantes}

Participaram desse estudo seis pais de crianças com SD, cujos filhos tinham idades entre nove meses e três anos e três meses. Todos os pais viviam junto com a mãe da criança com $\mathrm{SD}$ e eram residentes da grande Porto Alegre, com idades entre 26 e 46 anos, e de nível sócio-econômico variado. Dentre os participantes do estudo, quatro foram contatados através de uma instituição de atendimento para crianças com necessidades especiais, um através de encontro relacionado a crianças com SD, e um através de associação de familiares de crianças com SD. A Tabela 1 apresenta dados demográficos dos participantes.

\section{Delineamento e Procedimentos}

Foi utilizado um delineamento de estudo de caso coletivo (Stake, 1994), com vistas a investigar o envolvimento paterno 
e a experiência de paternidade no contexto da SD, com destaque para as particularidades e semelhanças entre os casos. Os pais contatados que concordaram em participar do estudo responderam inicialmente, por telefone, à Ficha de Contato Inicial (GIDEP, 1998a), a qual teve por objetivo, selecionar os possíveis participantes. Neste primeiro contato era então agendado um encontro com cada participante, em data mais conveniente para estes, sendo que todos escolheram sua própria residência como local de preferência para a realização da entrevista. No encontro com os pais eles inicialmente assinavam o Termo de Consentimento Livre e Esclarecido (GIDEP, 1998b) e depois respondiam à Entrevista de Dados Demográficos (GIDEP, 1998c), cujo objetivo era obter algumas informações como: idade, estado civil, profissão. Em seguida era realizada a Entrevista sobre paternidade e envolvimento paterno no contexto da Sindrome de Down (NUDIF, 2005), que procurou investigar o envolvimento paterno e a experiência da paternidade no contexto da SD, em particular os seus sentimentos em relação à paternidade e à síndrome. Esta entrevista foi baseada em outras similares (Silva \& Piccinini, 2001; GIDEP/NUDIF, 2004) e é composta de um conjunto de blocos de questões que investigam diversos temas como: gestação, parto e primeiros dias com os filhos; reações e sentimentos dos pais frente à notícia do diagnóstico; aspectos do desenvolvimento e do relacionamento pai-filho; sentimentos e mudanças frente à paternidade. Todas as entrevistas foram registradas em gravador digital e, posteriormente, transcritas para análise.

\section{Resultados e Discussão}

Análise de conteúdo qualitativa (Bardin, 1977; Laville \& Dionne, 1999) foi utilizada para investigar as respostas dos pais à entrevista sobre a paternidade no contexto da SD. Após a transcrição, foi realizada uma leitura exaustiva de todas as entrevistas, com o objetivo de organizar o relato dos pais em duas categorias temáticas baseadas na literatura e nas próprias respostas dos pais, a saber: Envolvimento Paterno e Experiência da Paternidade. A seguir, serão apresentados os resultados da análise, descrevendo brevemente cada categoria temática e ilustrando-as com relatos dos próprios pais ${ }^{4}$. Durante a análise procurou-se destacar as particularidades e semelhanças entre os casos, discutindo-as com base na literatura sobre o tema.

\section{Envolvimento Paterno}

Dentro desta categoria foram incluídos os relatos dos pais que versaram sobre o modo como eles participavam da vida de seus filhos, levando-se em consideração os três aspectos constitutivos do envolvimento paterno, descritos anteriormente: interação, acessibilidade (disponibilidade) e responsabilidade.

4 Na dissertação de mestrado da qual o presente estudo deriva são apresentados inúmeros outros exemplos dos relatos dos pais, os quais não foram incluídos no presente artigo para reduzir sua extensão. Algumas falas foram aqui também editadas, tendo em vista as limitações editoriais, sem que isto comprometesse seu sentido original.
A interação dos pais com seus filhos foi analisada a partir do relato dos participantes a respeito dos cuidados e atividades compartilhadas com eles ou com a esposa, desde o período gestacional, bem como sobre o relacionamento pai-filho após o nascimento. Incluíram-se aqui as percepções e expectativas dos pais sobre o desenvolvimento e futuro dos filhos, sobre o temperamento deles, assim como suas avaliações deste relacionamento.

Quanto ao período gestacional, todos os pais entrevistados se disseram bastante participativos, procurando auxiliar suas esposas nos momentos de maior dificuldade. Esta participação ocorreu através da ajuda nas tarefas rotineiras da casa, assim como nos momentos de desconforto da esposa, ocasionados pela gravidez, expressa inclusive pelos dois pais que souberam do diagnóstico de SD ainda durante gestação. Assim como na gestação, nos primeiros dias após o parto todos os pais mencionaram uma participação ativa nos cuidados e atividades relacionadas ao bebê. A interação com o filho foi referida tanto através de momentos de carinho para com ele, quanto na participação direta nos cuidados. Num dos casos (P2) ${ }^{5}$, em função da rejeição inicial da mãe para com o bebê, o pai assumiu o papel de principal cuidador, realizando todos os cuidados do filho: "Eu que dava banho, eu que trocava, porque ela [mãe] não queria pegar nele. Então eu fiz essa coisas de primeiro banho, pegar o umbiguinho que caiu" (P2).

Em relação à interação com o filho na época da entrevista, foram muitas as formas de participação em atividades e cuidados relatados pelos pais, tais como: levar a consultas médicas, dar comida, mamadeira e remédio, vestir, arrumar, brincar, levar em passeios, colocar para dormir e trocar fraldas: "Brincar em casa, no chiqueirinho. Sempre que a gente vai na pracinha, eu visto ele, arrumo para levar na estimulação, troco ele. Pego o leite dele, dou a mamadeira" (P6).

De modo geral percebeu-se, através deste estudo, que os pais se apresentavam bastante participativos nos cuidados e atividades relacionados aos filhos, desde o período gestacional, até o momento da entrevista. Este resultado parece confirmar a tendência assinalada por alguns autores (Cabrera, Tamis-LeMonda, Bradley, Hofferth \& Lamb , 2000; Lewis \& Dessen, 1999; Parke, 1996) de que os pais vêm se apresentando como mais envolvidos e participativos na vida de seus filhos.

Um aspecto importante em relação a este tema diz respeito à possível interferência do trabalho do pai sobre a sua participação nas atividades e cuidados com o filho. Um dos pais (P4) relatou que, devido ao trabalho, não vinha podendo acompanhar certas atividades da filha, como a ida às consultas médicas ou à terapia ocupacional, fonoaudiologia e outros tratamentos realizados por ela. Por outro lado, num dos casos (P3), como o pai estava desempregado, ele ficou encarregado do cuidado diário com a criança, pois era com ele que a filha permanecia a maior parte do tempo: "Como a mãe dela trabalha, eu dou comida, troco, dou lanche. Eu fazia com os outros [filhos], só que com a [filha com SD] eu estou mais envolvido diretamente" (P3).

5 O "P" seguindo do número identifica os participantes do presente estudo, conforme descrito na Tabela 1. 
A influência do trabalho dos pais sobre a relação com os filhos foi um tema discutido por diversos autores (Lamb, 1997; Lewis \& Dessen, 1999; Parke, 1996; Pleck, 1997), os quais ressaltam que questões institucionais, como as características do emprego dos pais, constituem uma das importantes razões para a ocorrência de baixos níveis de envolvimento paterno. Para Parke (1996), pais que estão altamente comprometidos com o trabalho, e que gastam longas horas no emprego, tendem a ser menos envolvidos nas atividades de pai. No entanto, este mesmo autor pondera que uma maior quantidade de envolvimento com os filhos não significa necessariamente uma melhor qualidade deste envolvimento.

Quando questionados diretamente sobre a influência da SD no desenvolvimento dos filhos, a maioria dos entrevistados (P1, P2, P3, P5) confirmou que esta provocou atraso no desenvolvimento. Este atraso ficou mais evidente para aqueles pais (P1, P2, P3) que já haviam convivido com outros filhos ou crianças na mesma faixa etária e que já faziam coisas que seus filhos com SD ainda não conseguiam: "Então quando eu vou na escolinha buscá-lo, eu percebo no tamanho, que uma criança de três anos já está falando tudo, e ai é que eu vejo que há uma diferença bem grande! Eu sei que a Síndrome de Down acompanha uma deficiência mental moderada ou não. Mas aí eu percebo que há uma diferença de conduta, de comportamento, de uma criança que não tem a sindrome" (P2).

É interessante notar que um dos pais (P3), percebendo esse atraso no desenvolvimento da filha pela experiência anterior com seus outros filhos, destacou um aspecto positivo, pois, para ele, ela permaneceria um bebê por mais tempo. Assim, pareceu que este pai tentou transformar o que seria fonte de preocupação, em algo positivo, como uma forma de lidar melhor com a situação e com as limitações impostas pela SD: "Ela está com um ano e cinco meses. Com essa idade os outros já corriam, caminhavam, falavam, coisa que ela não faz. É o retardo que a Síndrome de Down dá em tudo. Isso eu noto bastante. Mas a vantagem da Síndrome de Down é que a criança vai ser bebê por muito tempo, que é a melhor fase da criança! Porque ela está com um ano e cinco meses e ainda é bebê! Coisa que outros não são mais bebê, são criancinhas" (P3).

As limitações advindas da síndrome, assinaladas pelos pais na convivência com seus filhos, são também discutidas por alguns autores, os quais apontam um retardo na aquisição de algumas habilidades. McConnaughey e Quinn (2007) mencionam que, em função de as crianças com SD funcionarem nos limites entre uma deficiência intelectual leve à moderada, elas provavelmente aprenderão certas habilidades mais lentamente, o que não implica necessariamente em incapacidade para aprender. Dentro deste contexto, um outro aspecto presente nos relatos dos pais do presente estudo, e que também foi apontado por outros autores, é a percepção, por parte de alguns pais, de que o filho com SD apresentava problemas de comportamento, atenção e imaturidade (Cuskelly \& Dadds, 1992; Roach, Orsmond \& Barratt, 1999; Stores, Stores, Fellows \& Buckley, 1998). Entretanto, não há consenso se este último aspecto se daria em função da própria síndrome, ou devido a uma dificuldade na imposição de limites por parte dos pais.
Ao falar sobre as expectativas em relação ao futuro dos filhos, os pais trouxeram questões relacionadas ao trabalho, estudo e ao bom desenvolvimento deles (P1, P2, P4, P5, P6). $\mathrm{O}$ que se percebe é que alguns pais ( $\mathrm{P} 1, \mathrm{P} 4)$ apresentaram expectativas mais elaboradas do que outros, ao esperar que os filhos conseguissem cursar uma faculdade: "A expectativa agora é a melhor, porque estou tendo informações de que pessoas com SD estão na universidade, estão trabalhando, estão normal. Essa é a minha expectativa, fazer o máximo pra ele se tornar uma pessoa praticamente normal, ter uma qualidade de vida boa" (P1).

Este tipo de expectativa também esteve presente para um dos pais entrevistados por Silva e Dessen (2003), o qual considerava que seu filho teria facilidade nos estudos e conseguiria concluir um curso superior. Segundo as autoras tais expectativas podem ser caracterizadas como exageradamente altas e inapropriadas frente ao quadro da SD. Além disso, algo que também coincide com os resultados da referida pesquisa é a menção dos pais do presente estudo que se propunham a fazer tudo o que estivesse ao seu alcance para que a criança conseguisse se desenvolver ao máximo ou, como disse um dos pais, para que ele se tornasse uma pessoa "praticamente normal". Silva e Dessen acrescentam, contudo, que este comportamento pode fazer com que os pais ignorem as limitações da criança, representando, por isso, uma tentativa de aliviar o sentimento de culpa que eles possam estar sentindo.

No que diz respeito ao temperamento dos filhos, a maioria dos pais ( $\mathrm{P} 2, \mathrm{P} 4, \mathrm{P} 5, \mathrm{P} 6)$ destacou características positivas, como: carinhosos, calmos, bem-humorados, amorosos, brincalhões, e alegres: "Eu acho que ele é calmíssimo, calmíssimo. Ele dorme rindo e acorda rindo!" (P6). Em dois casos (P1, P3) os pais relataram que os filhos apresentavam um temperamento mais difícil de lidar, o qual foi atribuído à síndrome através da comparação que os pais faziam com outras crianças sem deficiência, bem como pela referência a familiares de outras crianças com SD, que também as julgavam difíceis. Por vezes, mesmo características comuns entre crianças sem deficiência, quando apareciam no contexto da $\mathrm{SD}$, passavam a ter um significado particular: "Como a gente já conversou com pessoas que tem filhos com Síndrome de Down, é bem dificil. Ela é bem geniosa! Casualmente tem o filho de uma mulher que mora aqui ao lado e que também tem Sindrome de Down, e a mãe dele disse: 'Te prepara porque eles são danados! Eles são danados! A criança com Síndrome de Down é danada" (P3).

Vários achados do presente estudo vão ao encontro daqueles descritos por Hornby (1995), em que pais de crianças com SD relataram mais uma impressão positiva do que negativa sobre seus filhos. Assim como as características consideradas pelos pais como mais difíceis de lidar foram associadas à síndrome, um dos pais (P1) caracterizou seu filho como carinhoso e afetuoso, também relacionando tal particularidade ao fato de ele ter SD. Existe uma noção antiga de que as crianças com SD têm um bom temperamento, são afetuosas e agradáveis (Stores \& cols., 1998), a qual parece persistir até os dias de hoje. No entanto, estes mesmos autores contestam tal estereótipo, assim como Newcombe (1999), que diz que a crença de que crianças com SD sejam particularmente alegres e sociáveis parece ter pouca base em 
fatos reais, mesmo que seu desenvolvimento social possa se dar em um passo um pouco mais acelerado do que seu desenvolvimento cognitivo. Além disso, segundo Cahill e Glidden (1996), a imagem popular de que são crianças mais fáceis de lidar, acaba também influenciando a família de um modo menos negativo do que com crianças com outros tipos de deficiência como o autismo.

No que diz respeito à relação pai-filho em geral, todos os pais fizeram uma avaliação positiva, considerando que conseguiam estabelecer um bom relacionamento com seus filhos. Dentro deste contexto, alguns pais (P2, P4) percebiam que a influência da SD sobre o relacionamento pai-filho estava, muitas vezes, relacionada aos aspectos do desenvolvimento pontuados anteriormente por eles, como o atraso e maiores dificuldades na compreensão de regras: "De vez em quando, não sei se é pela criança ou pela SD, mas tu tem que falar mais de duas, três vezes. Então tem vezes que eu falo com ela e ela finge que não escuta e faz o que não era para fazer. Isso eu acho que afeta um pouco" (P4).

Já a disponibilidade de tempo dos pais para estarem com seus filhos, segunda dimensão analisada dentro do conceito de envolvimento paterno, pareceu estar relacionada à jornada de trabalho (P1, P2, P4, P5) e/ou à escola desses pais (P1), e da flexibilidade de horário no emprego (P6). Foi justamente a disponibilidade de tempo para estar com o filho que se apresentou como uma queixa de dois pais entrevistados (P4, P5), sendo que para um deles, o pouco tempo para estar com a filha pareceu suscitar culpa, cuja tentativa de compensação era feita através de bens materiais, principalmente brinquedos de estimulação: “Às vezes eu me culpo de não ter tempo para ela. Não sei se é algo automático, mas eu tento com bens materiais me satisfazer como pai, para ela. Sempre comprando brinquedo, coisas, cadeiras de estimulação, mesa de estimulação, tudo porque eu não vou estar ali, mas ela vai ter um brinquedo que vai deixá-la sempre estimulada” (P4).

Quanto à responsabilidade dos pais em relação aos seus filhos, terceiro aspecto constitutivo do conceito de envolvimento paterno, esta englobou os relatos dos pais a respeito de preocupações com eles, participação nas decisões sobre suas vidas, conversas com a esposa sobre assuntos relacionados a eles e gastos financeiros com eles.

Tanto durante o período da gestação quanto na época do parto, uma das preocupações mais referidas pelos pais (P1, P3, P4, P5, P6) foi a de que seus filhos viessem com saúde. Isso foi mencionado mesmo nos casos em que os pais já sabiam do diagnóstico para SD nestes períodos (P1, P5): "Só que viesse saudável. Sem nenhum probleminha, não o que ela teve agora [SD], que a gente foi descobrir quando fez a eco" (P5). Para alguns pais (P3, P4, P6) tal preocupação permanecia no momento da entrevista, especialmente nos períodos em que o filho adoecia. Esta preocupação pareceu ser bastante proeminente para estes pais, visto que eles percebiam seus filhos como frágeis e mais vulneráveis a doenças quando comparados com crianças sem deficiência.

Foi nos primeiros dias de convivência com o filho que os participantes passaram a lidar com o fato de serem pais de uma criança com $\mathrm{SD}$, o que suscitou muitas dúvidas e receios, especialmente relacionados à saúde, desenvolvimento e vida social dos filhos. Tais receios, ao menos neste momento inicial, pareciam muito ligados ao desconhecimento da síndrome e de como manejar possíveis limitações ainda incertas com as quais eles poderiam se deparar futuramente (P1, P2, P3, P5): "Sobre o desenvolvimento dela, como seria. Como lidar com uma criança com SD. 'Será que ela vai fazer isso? Será que ela vai fazer aquilo'?" (P3).

Alguns autores apontam que os pais de crianças com SD enfrentam dificuldades no cuidado com a saúde de seus filhos (Cunningham, 1996; Roach \& cols., 1999). Tal apreensão parece ter assumido uma conotação particular frente à presença da $\mathrm{SD}$, por estes pais tomarem conhecimento de que existem alguns problemas de saúde que são comuns a esta síndrome. De fato, as crianças com SD apresentam uma incidência mais alta de intercorrências clínicas, como: problemas cardíacos, gastrintestinais, visuais, auditivos, bem como uma maior propensão a infecções (Kozma, 2007). Sendo assim, os problemas clínicos apresentados pela criança com SD podem somar-se às outras dificuldades próprias desta síndrome, aumentando o eventual estresse vivenciado pela sua família (Jarrett, 2007).

A preocupação com o futuro do filho e com a sua capacidade de desenvolvimento foi outra preocupação referida pelos pais, em especial nas primeiras semanas após o nascimento. De acordo com Lamb e Billings (1997), existe uma tendência de os pais, mais do que as mães de crianças com qualquer deficiência, apresentarem preocupações com os efeitos a longo prazo da deficiência. Preocupações com o futuro dos filhos também apareceram no estudo de Hornby (1995), visto que $36 \%$ dos 90 pais entrevistados cujos filhos tinham SD relataram preocupações relativas ao suporte para a criança depois da idade escolar, ou quando os pais ficassem velhos ou doentes, seguido por preocupações com a educação (20\%) e a saúde (18\%) dos filhos.

A preocupação com a saúde e desenvolvimento esteve presente também nas conversas que os pais do presente estudo referiram ter com suas esposas. Por essa razão, para um dos pais, esse momento de conversa foi percebido como algo negativo, pois trazia à tona as possíveis limitações de sua filha, algo que ele parecia querer negar. Como já foi mencionado anteriormente, a negação pode fazer parte dessa experiência, sendo que o nascimento de uma criança com SD é considerado como um evento que leva à perda de fantasias e mitos, e cujo desafio se dá em reescrever metas futuras (King \& Patterson, 2000).

Em praticamente todos os casos os pais eram os únicos responsáveis $(\mathrm{P} 4, \mathrm{P} 5, \mathrm{P} 6)$, ou os principais responsáveis $(\mathrm{P} 2)$, pelo provento financeiro da família e dos filhos. Isso se devia ao fato, principalmente, de a maioria das mães (P1, P4, P5, P6), por necessidade e/ou opção, não estarem empregadas quando foi realizada a entrevista.

\section{Experiência da Paternidade}

Nesta categoria foram incluídos os relatos dos participantes referentes a sua experiência como pais de uma criança com SD, com destaque para os aspectos subjetivos. Para tanto, foram analisados os relatos dos pais quanto à reação e aos sentimentos suscitados pela notícia do diagnóstico, conhecimentos a respeito da $\mathrm{SD}$, mudanças advindas da 
paternidade e influência da SD sobre suas experiências de paternidade.

Em relação à notícia do diagnóstico, dos seis pais entrevistados, quatro (P2, P3, P4, P6) souberam da SD após o nascimento da criança, enquanto dois já sabiam desde o período pré-natal. No primeiro grupo, após o nascimento, eles ouviram primeiramente sobre as suspeitas desse diagnóstico, que só viria a ser confirmado após o exame genético. Desses quatro casos, em apenas um (P6) a suspeita da SD foi exposta para o casal, sendo que nos outros três (P2, P3, P4) esta hipótese foi colocada para a mãe, num momento em que ela estava sozinha: "A gente soube dois ou três dias após o nascimento. A médica desconfiou no primeiro dia, aí falou dos olhos, das sobrancelhas, enfim. 'Mas a gente vai fazer alguns exames' [disse a médica]. Aíficou a expectativa de se saber se tinha ou não, mas eu sinceramente, já vi que tinha. Não sei por quê, eu disse: 'Se essa médica veio com esse papo de desconfiar, é porque tem, mas só depois dos exames eles vão falar'. Foi o que aconteceu" (P3).

A notícia do diagnóstico para SD foi algo que suscitou nos pais diversos sentimentos. Independente de saberem já no pré-natal ou após o parto, em geral, eles relataram sentimentos de choque, tristeza, lamento, nervosismo e preocupações sobre como seria a vida do filho: "Ah, eu fiquei triste, né. Triste não porque o meu filho vai ter síndrome, não. Mas triste porque aquela coisa assim, eu ficava preocupado, se ele não vier com saúde, se ele vier com uma má formação que pode ter né, ou algum problema cardíaco" (P1).

Num dos casos (P6) em que a suspeita do diagnóstico foi mencionada após o nascimento, a confirmação deste, através do teste genético, foi sentida pelo pai como algo que acabou com a esperança de que o filho não tivesse SD: "Não tinha caído a ficha ainda. Eu acho que foi uma coisa que tu sabe, mas não quer. Não é não querendo, mas aquela pontinha de esperança que não era. Mas ela falando isso foi só um jeito de terminar, como se fosse uma chama acessa e jogassem um balde de água fria e apagasse. Acabou! Agora é realidade! A gente queria um filho, agora ele já está aí e vamos tratar ele normal" (P6).

Assim como já assinalado por Schwartzman (2003), neste estudo, de modo geral, também foram as características fenotípicas da criança, ou seja, a presença de traços característicos da SD, que justificaram o diagnóstico logo após o seu nascimento. Entretanto, o que se percebeu, algumas vezes, foi que apenas frente ao resultado do exame de cariótipo é que os pais tiveram certeza de que seus filhos tinham SD. Sendo assim, uma das reações dos pais frente à suspeita do diagnóstico foi a de inicialmente questioná-lo. De acordo com alguns autores (Garcias \& Roth, 2004; Lamb \& Billings, 1997; Oliveira, 2001; Pupo Filho, 1996), essa é uma das reações possíveis frente a tal situação, sendo o resultado do exame o representante do confronto final, ou seja, aquele que traz à tona a realidade inesperada, a qual não se pode mais negar.

Muito da reação dos pais esteve permeada pelo modo como suas esposas reagiram, as quais, segundo alguns (P1, P2, P3, P4), apresentaram muita dificuldade em passar por este momento. Sendo assim, mais do que vivenciar a sua própria dor, alguns pais ( $\mathrm{P} 2, \mathrm{P} 3, \mathrm{P} 4)$ tiveram que se preocupar em dar o apoio emocional necessário para suas esposas:
“Eu não consegui pensar em outra coisa a não ser cuidar dela [esposa] que estava em crise. Não pude nem sentar e chorar. Eu tive que permanecer bem. Mas quando eu cheguei em casa, eu desmoronei! Fui tomar um banho e... Mas foi o único momento em que eu me permiti! E a partir dai eu assumi tudo e nunca mais voltei a derramar uma lágrima" (P2).

Os achados pareceram confirmar a idéia defendida por Oliveira (2001) de que o impacto do diagnóstico é maior para as mães do que para os pais. Isso pôde ser percebido nos casos em que os pais relataram que as esposas sofreram muito frente à notícia, fazendo com que eles desempenhassem, naquele momento, o papel de apoiadores. Alguns pais deste estudo destacaram particularmente esta preocupação com os sentimentos de suas esposas frente à notícia da $\mathrm{SD}$, em detrimento de falar sobre seus próprios sentimentos, o que apóia os achados semelhantes destacados na literatura (Herbert, 1995). Entretanto, assim como foi colocado por este autor, pode-se cogitar também que esta atitude paterna pode estar associada a questões culturais, visto que, muitas vezes, é esperado pela sociedade que o homem seja o esteio da família, sendo capaz de suportar as situações difíceis sem ficar tão abalado.

Dos seis pais entrevistados, cinco (P1, P2, P3, P5, P6) relataram nunca ter tido contato mais próximo com pessoas com SD e, por esse motivo, pouco sabiam a respeito desta síndrome. Muito do que os pais mencionaram saber sobre a SD na época do diagnóstico envolveu questões relacionadas mais à aparência física das pessoas com $\mathrm{SD}$, como os olhos puxados, a língua protusa, e também ao retardo mental apresentado pelas mesmas: "O que eu sabia era que eram crianças que não tinham um desenvolvimento normal, um problema de fala, normalmente tem a lingua para fora, mas isso de ver" (P3).

Alguns pais (P3, P6) colocaram que tal desconhecimento a respeito da SD se justificava pelo fato de nunca terem tido um caso na família ou em pessoas próximas, o que não lhes deu motivos para que, antes do nascimento de seus filhos com $\mathrm{SD}$, se informassem sobre este assunto. Ou seja, até então, esta era uma realidade da qual eles não faziam parte, que se tornou presente em suas vidas com a chegada do filho com SD: "Até então eu não sabia de nada. Não sabia o que era [SD]. Geralmente tu só vai procurar essa informação quando tem na tua família" (P6).

Assim como o que foi encontrado no estudo de Silva e Dessen (2003), os participantes desta pesquisa não tinham conhecimentos sobre a SD antes do diagnóstico dos filhos, e foi a necessidade de conviver com esta situação que fez com que buscassem informações, através de livros, revistas e outras fontes (P4, P5, P6). Da mesma forma, os dois estudos demonstraram o reconhecimento, por parte dos pais ( $\mathrm{P} 2$, P6), sobre a necessidade e importância da estimulação para o desenvolvimento da criança. Em outra pesquisa, realizada por Rodrigue, Morgan e Geffken (1992), foi constatado que os pais das crianças com SD utilizaram muito mais a estratégia de enfrentamento de "busca por informações", do que pais de crianças não deficientes. Esta busca de informações sobre as condições da criança e sobre o que poderia ser feito para melhorar ou facilitar o desenvolvimento dela, foi vista pelos autores como sendo uma resposta adaptativa à situação vivenciada. Além disso, de acordo com Stratford (1997), a 
compreensão da dimensão biológica da $\mathrm{SD}$, tanto por pais, quanto por profissionais que trabalham com crianças com a síndrome, apesar de não ajudar a prever o futuro destas crianças, pode evitar a susceptibilidade a falsas crenças a respeito da SD. Isso porque tal conhecimento, segundo o autor, pode fornecer uma base firme para a busca de progressos em áreas acessíveis ao atendimento, tais como: educação, aprendizagem, autoconfiança, questões psicológicas, aquisição de habilidades, trabalho, independência e cuidados próprios, os quais contribuem para uma vivência digna. Isso foi também constatado no presente estudo, em que o conhecimento adquirido pelos pais os fez tomar consciência do papel e da importância da estimulação na vida de seus filhos.

No que diz respeito às mudanças advindas da paternidade, chamou a atenção que alguns pais mencionaram uma diferença em sua percepção da deficiência em geral (P2, P3). $\mathrm{O}$ fato de serem pais de uma criança com SD pareceu ter feito com que eles começassem a fazer parte de um mundo que antes não lhes era familiar, passando a prestar mais a atenção e convivendo mais com outras pessoas com deficiência e suas famílias: "O que mudou foi essa percepção do mundo em relação à inclusão, ao deficiente. Porque como todas as outras coisas, só acontece com os outros o que não é bom, a morte, o acidente, acontece com os outros. Então o que mudou na minha vida foi a presença daquela coisa que geralmente se diz: 'Nossa! Que desgraça!'Porque estava lá e de repente está aqui próximo. Então eu comecei a participar desse mundo que antes eu não passava perto. Tu começas a conviver num mundo que normalmente não é o teu mundo!" (P2).

Quando questionados diretamente a respeito da influência da SD sobre a sua experiência de paternidade, muitos pais (P1, P3, P4, P5, P6) mencionaram não perceber tal influência. Um deles (P6), entretanto, mesmo negando esta influência, trouxe questões que pareceram demonstrar preocupações referentes à integração do filho na sociedade: "Não afeta em nada, até porque eu não dou bola, até porque a sociedade está com a mente mais aberta. Eu sei que quem vai cuidar dele sou eu, sei que quem vai dar as coisas para ele sou eu. Mas não me preocupo agora com a sociedade, apesar de saber que vai chegar uma hora que ele vai ter que se integrar à sociedade, como escola, igreja" (P6). De forma semelhante, um segundo pai (P1), apesar de também negar diretamente esta influência, apresentou um discurso contraditório, ao demonstrar a percepção de que ter um filho com deficiência se caracterizava por uma experiência diferente de paternidade, fazendo dele um "super pai", ou seja, um pai especial: "Olha, eu acho que não afeta! Na boa, eu acho que não afeta. Eu acho que, assim como tem aquele programa 'Super Nanny', eu acho que eu vou ser um super pai, né! Eu acho que tu ter um filho especial, em vez de ser pai, tu te torna um super pai" (P1).

Outro pai (P2) referiu que esta influência pode estar relacionada a certas limitações advindas de ser pai de uma criança com SD, as quais pareciam impor restrições em sua vida. Tais limitações, ao que parece, aconteciam em função de determinados comportamentos do filho, os quais exigiam uma conduta adaptada por parte do pai: "Se ele não tivesse [SD] algumas coisas seriam diferentes. Talvez uma brincadeira fosse diferente, uma conduta, a alimentação seria diferente, mas o resto... Tudo o que é possível eu faço com ele! Um pouco tenso! Será que ele não vai virar isso aqui? Ele adora ir ao supermercado e pegar as coisas da prateleira... E os outros [filhos]: 'Não pega que tu vais quebrar isso ai!'. Eles reconheciam, obedeciam a essas ordens simples. Só que eu não sei se ele faz isso pela questão da deficiência mental, se ele está mesmo a fim de derrubar, ou ele está desobediente porque ainda não foi colocado nele a questão do limite" (P2).

A possível restrição imposta à vida dos pais e mães pela presença de uma criança com SD foi um dos temas investigados por Sanders e Morgan (1997). Em seu estudo, estes autores constataram que mães de crianças com deficiência participavam menos de atividades recreativas e esportivas do que mães de crianças sem deficiência, confirmando a existência destas restrições. As restrições impostas à família pela presença de uma criança com SD também estiveram presentes no relato de grande parte dos pais entrevistados por Hornby (1995). Contudo, nem todos os estudos apontam nesta direção, como é o caso da investigação de Hedov, Annerén e Wickblad (2000), cuja pesquisa apontou que ter uma criança com SD na família não afetou as atividades sociais dos pais e mães, embora tenha levado a déficits em sua saúde. Já, no caso do presente estudo, como não foi realizada uma comparação entre pais de crianças com SD e pais de crianças sem deficiência, não há como afirmar se as restrições apontadas pelos pais estão relacionadas ao fato de seu filho ter SD ou, simplesmente, a questões relativas à paternidade em si.

\section{Considerações Finais}

Embora possamos identificar muitas semelhanças nos relatos dos pais a respeito da paternidade no contexto da $\mathrm{SD}$, o que se sobressai são as inúmeras particularidades de cada participante do presente estudo. Esse é um dos aspectos que fazem da pesquisa qualitativa algo tão rico, a ponto de ajudar a compreender melhor as vivências particulares de cada caso. Embora possam ser encontradas semelhanças na paternidade destes pais, os resultados deste estudo não permitem estabelecer um padrão característico que possibilite abarcar toda a variabilidade de situações possíveis num contexto tão complexo quanto o da SD. O nascimento de um filho com SD atinge os pais de diferentes maneiras, interferindo tanto no envolvimento deles com seus filhos, quanto nas suas experiências de paternidade. De qualquer forma, apesar das dificuldades, tanto objetivas (financeiras, tempo, emprego), como mais subjetivas (aceitação, tristeza, preocupação), eles demonstraram uma boa adaptação ao filho com SD, conseguindo exercer bem seu papel de pai.

Como a presente pesquisa não envolveu comparação entre pais de crianças com SD e pais de crianças sem deficiência, não se pode afirmar que alguns dos resultados encontrados aqui sejam característicos apenas do contexto da SD, já que podem, pelo menos parcialmente, serem dificuldades que afetam qualquer pai, nos novos papeis de cuidadores que eles têm assumido, independente dos contextos. Além disto, cabe lembrar que todos os participantes faziam parte de ONGs ou centros de atendimento para crianças com deficiência, fato que, de antemão, pode indicar um maior envolvimento 
e preocupação destes pais para com seus filhos, bem como uma maior sensibilidade frente às demandas da paternidade. Soma-se a isto, o fato de que aceitar participar de um estudo que envolvia uma entrevista detalhada sobre a paternidade e que investigava aspectos pessoais pode indicar que estes pais se constituíam em um grupo de pais diferentes daqueles que nem se interessaram em participar do estudo.

Ademais, os participantes deste estudo eram pais de crianças com poucos anos de vida e, talvez, não tivessem ainda experienciado dificuldades próprias das fases posteriores do desenvolvimento, que implicam na aceitação de limites, numa acentuada socialização e na escolarização. Por esse motivo, é importante que sejam realizados novos estudos que investiguem o impacto da SD sobre o envolvimento paterno e sobre a experiência de paternidade ao longo de diferentes fases de desenvolvimento da criança, para que assim se entenda melhor as particularidades desta vivência.

Há que se considerar ainda que os familiares de crianças com SD fazem parte de um universo particular, que parece estar permeado por mitos e estigmas relacionados à deficiência intelectual. Muitas vezes, durante as entrevistas, teve-se a impressão de que os pais foram cuidadosos ao falar dos filhos, talvez por receio de que algumas colocações pudessem reforçar estigmas e preconceitos tão presentes nesta realidade. Sendo assim, os resultados podem, de alguma forma, estar permeados por esse cuidado dos pais em falar sobre os filhos, particularmente em função da época em que o estudo foi realizado, em que a mídia televisiva estava destacando atitudes politicamente corretas em relação à SD, especialmente durante uma novela apresentada no horário nobre, que tinha com protagonista uma menina com a síndrome.

De qualquer modo, este estudo contribuiu para aprofundar o conhecimento a respeito da paternidade no contexto da SD, ainda pouco estudado na literatura nacional e internacional. Tendo em vista as dificuldades vivenciadas pelos pais neste contexto, é importante ressaltar a necessidade, já citada por vários autores (Cunningham, 1996; Hornby, 1995; Pelchat, Bisson, Ricard, Perreault \& Bouchard, 1999; Silva \& Dessen, 2003; Sloper, Knussen, Turner \& Cunningham, 1991), de se desenvolver ações que auxiliem não somente os pais, mas também as mães e os demais membros da família a lidar melhor com as particularidades advindas desta vivência, podendo ajudar a proporcionar uma melhor qualidade de vida para estas famílias e contribuir para um melhor desenvolvimento da criança com SD.

\section{Referências}

Bardin, L. (1977). Análise de Conteúdo. São Paulo: Edições 70. Cabrera, N. J. Tamis-LeMonda, C. S. Bradley, R. H. Hofferth, S., \& Lamb, M. E. (2000). Fatherhood in the twenty-first century. Child Development, 71(1), 127-136.

Cahill, B. M., \& Glidden, L. M. (1996). Influence of child diagnosis on family and parental functioning: Down Syndrome versus other disabilities. American Journal on Mental Retardation, 101, 149-160.

Cunningham, C. C. (1996). Families of children with Down Syndrome. Down Syndrome Research and Practice, 4(3), 87-95.
Cuskelly, M., \& Dadds, M. (1992). Behavioural problems in children with Down's Syndrome and their siblings. Journal of Child Psychology and Psychiatry, 33(4), 749-761.

Dessen, M. A., \& Silva, N. L. P. (2000). Deficiência mental e família: Uma análise da produção científica. Cadernos de Psicologia e Educação Paidéia, 10, 12-23.

Garcias, G. L., \& Roth, M. G. (2004). Conversando sobre a Sindrome de Down. Pelotas: Educat.

GIDEP - Grupo de Interação Social, Desenvolvimento e Psicopatologia. (1998a). Ficha de Contato Inicial. Manuscrito não-publicado, Instituto de Psicologia, UFRGS, Porto Alegre.

GIDEP - Grupo de Interação Social, Desenvolvimento e Psicopatologia. (1998b). Termo de Consentimento Livre e Esclarecido. Manuscrito não-publicado, Instituto de Psicologia, UFRGS, Porto Alegre.

GIDEP - Grupo de Interação Social, Desenvolvimento e Psicopatologia. (1998c). Entrevista de dados Demográficos do Casal. Manuscrito não-publicado, Instituto de Psicologia, UFRGS, Porto Alegre.

GIDEP/NUDIF - Grupo de Interação Social, Desenvolvimento e Psicopatologia. (2004). Entrevista sobre a gestação e o parto. Manuscrito não-publicado, Instituto de Psicologia, UFRGS, Porto Alegre.

Hedov, G., Annerén, G., \& Wikblad, K. (2000). Self-perceived health in Swedish parents of children with Down's Syndrome. Quality of Life Research, 9, 415-422.

Henn, C. G. Piccinini, C. A., \& Garcias, G. L. (2008). A família no contexto da Síndrome de Down: Revisando a literatura. Psicologia em Estudo, 13(3), 485-493.

Herbert, E. (1995). Parents' reported responses to the disclosure of Down's Syndrome. Down Syndrome Research and Practice, 3(2), 39-44.

Hornby, G. (1995). Father's views of the effects on their families of children with Down Syndrome. Journal of Child and Family Studies, 4(1), 103-117.

Jarrett, M. H. (2007). A vida familiar com seu filho (M R. Lucena, Trad.). Em K. Stray-Gundersen (Org.), Crianças com Síndrome de Down: guia para pais e educadores (pp. 111-133). Porto Alegre: Artmed (Original published in 1995).

King, L., A. \& Patterson, C. (2000). Reconstructing life goals after the birth of a child with Down Syndrome: finding happiness and growing. International Journal of Rehabilitation and Health, 5(1), 17-30.

Kozma, C. (2007). Problemas clínicos e tratamentos (M. R. Lucena, Trad.). Em K. Stray-Gundersen (Org.), Crianças com Síndrome de Down: guia para pais e educadores (pp. 64-88). Porto Alegre: Artmed.

Lamb, M. E. (1997). Fathers and Child Development: An Introductory Overview and Guide. Em M. E. Lamb (Ed.), The role of the father in child development (pp. 1-18). New York: John Wiley \& Sons.

Lamb, M. E., \& Billings, L. A. L. (1997). Fathers of Children with Special Needs. Em M. E. Lamb (Ed.), The role of the father in child development (pp. 179-190). New York: John Wiley $\&$ Sons.

Lamb, M. E., Pleck, J. H., Charnov, E. L., \& Levine, J. A. (1985). Paternal behavior in humans. American Zoologist, 25, 883-894.

Laville, C., \& Dionne, J. (1999). A Construção do Saber. Porto Alegre: Artes Médicas. 
Lewis, C., \& Dessen, M. A. (1999). O Pai no Contexto Familiar. Psicologia: Teoria e Pesquisa, 15(1), 9-16.

McConnaughey, F., \& Quinn, P. O. (2007). O desenvolvimento da criança com Síndrome de Down (M. R. Lucena, Trad.). Em K. Stray-Gundersen (Org.), Crianças com Síndrome de Down: guia para pais e educadores (pp. 134-158). Porto Alegre: Artmed.

Newcombe, N. (1999). Desenvolvimento Infantil: abordagem de Mussen ( $8^{\mathrm{a}}$ ed.) (C. Buchweitz, Trad.) Porto Alegre: Artes Médicas.

NUDIF - Grupo de Interação Social, Desenvolvimento e Psicopatologia. (2005). Entrevista sobre paternidade e envolvimento paterno no contexto da Síndrome de Down. Manuscrito não-publicado, Instituto de Psicologia, UFRGS, Porto Alegre.

Oliveira, L. M. (2001). O desejo parental diante do impacto do diagnóstico de Síndrome de Down. Dissertação de Mestrado, Universidade Federal do Rio Grande do Sul, Porto Alegre.

Parke, R. D. (1996). Fatherhood. Cambridge, Massachusetts: Harvard University Press.

Pelchat, D. Bisson, J. Ricard, N. Perreault, M., \& Bouchard, J. M. (1999). Longitudinal effects of an early family intervention programme on the adaption of parents of children with a disability. International Journal of Nursing Studies, 36, 465477.

Pleck, J. H. (1997). Paternal Involvement: Levels, Sources and Consequences. Em M. E. Lamb (Ed.), The role of the father in child development (pp. 66-103). New York: John Wiley \& Sons.

Pupo-Filho, R. A. (1996). Síndrome de Down: e agora doutor? Rio de Janeiro: WVA.

Roach, M. A., Orsmond, G. I., \& Barratt, M. S. (1999). Mothers and fathers of children with Down Syndrome: Parental stress and involvement in childcare. American Journal on Mental Retardation, 104(5), 422-436.

Rodrigue, J. R., Morgan, S. B., \& Geffken, G. R. (1992). Psychosocial Adaptation of Fathers of Children with Autism, Down Syndrome, and Normal Development. Journal of Autism and Developmental Disorders, 22(2), 249-263.
Sanders, J. L., \& Morgan, S. M. (1997). Family Stress and Adjustment as Perceived by Parents of Children with Autism and Down Syndrome: Implications for Intervention. Child and Family Behavior Therapy, 19(4), 15-32.

Schwartzman, J. S. (2003). Generalidades. Em J. S. Schwartzman (Org.), Síndrome de Down (pp. 16-31). São Paulo: MemnonMackenzie.

Silva, M. R., \& Piccinini, C. A. (2001). Entrevista sobre a Paternidade e o Envolvimento Paterno. Manuscrito nãopublicado, Instituto de Psicologia, UFRGS, Porto Alegre.

Silva, N. L. P., \& Dessen, M. A. (2003). Crianças com Síndrome de Down e suas Interações Familiares. Psicologia: Reflexão e Crítica, 16(3), 503-514.

Sloper, P., Knussen, C., Turner, S., \& Cunningham, C. (1991). Factors related to stress and satisfaction with life in families of children with Down Syndrome. Journal of Child Psychology and Psychiatry, 32(4), 655-676.

Stake, R. E. (1994). Case Studies. Em N. Denzin \& Y. Lincoln (Eds.) Handbook of Qualitative Research (pp. 236-247). London: Sage.

Stores, R., Stores, G., Fellows, B., \& Buckley, S. (1998). Daytime behaviour problems and maternal stress in children with Down's Syndrome, their siblings, and non-intellectually disabled and other intellectually disabled peers. Journal of Intellectual Disability Research, 42(3), 228-237.

Stratford, B. (1997). Crescendo com a Síndrome de Down. Brasília: CORDE. 